\title{
UM ESTUDO ACERCA DOS EFEITOS E DAS CONTRIBUIÇÕES DO TRABALHO COM PRÁTICAS TEATRAIS PARA A FORMAÇÃO DE LEITORES LITERÁRIOS
}

\author{
A STUDY ABOUT THE EFFECTS AND CONTRIBUTIONS \\ OF WORK WITH THEATER PRACTICES FOR THE \\ FORMATION OF LITERARY READERS
}

Fernanda Cavalheiro Granato'

Fabiana Giovani ${ }^{2}$

\footnotetext{
1 Mestranda vinculada ao Mestrado Profissional em Ensino de Línguas da Universidade Federal do Pampa - UNIPAMPA. Email: granato.fc@gmail.com

2 Professora adjunta da Universidade Federal de Santa Catarina - UFSC. Email: fabiana.giovani@ ufsc.br
} 
RESUMO: $\mathrm{O}$ artigo tem por intuito apresentar os resultados de uma experimentação didática associada diretamente à criação e ao resgate de leitores literários. A proposta baseou-se nas práticas teatrais dentro da sala de aula como incentivo e fomento à leitura que cada vez mais encontram-se esquecidas pelas novas gerações. Em busca de uma amplitude que gerasse maior consistência ao trabalho, buscou-se referências em Zilberman (2003), Colomer (2007) e Silva (2009). As análises de cunho qualitativo nos mostraram a necessidade de os professores conhecerem o acervo da biblioteca das escolas e a importância de entenderem como se dá o processo de formação de leitores, visto que muitos alunos não se consideram leitores pelo fato de não lerem textos literários.

PALAVRAS-CHAVES: formação de leitores; práticas teatrais; leitores literários.

ABSTRACT: The following work is a didactic experimentation directly associated with the creation and rescue of literary readers. The author's proposal is based on the theatrical practices within the classroom as an incentive and encouragement for reading due to an obsolete educational system that did not reformulate the proposal of talking with the new students and new reading formats. In search of an amplitude that generated greater consistency in the work, the author sought practical and theoretical references, regarding theater history, in the following authors Zilberman (2003), Colomer (2007) and Silva (2009). Finally, we realize that in order to obtain greater results the work with theatrical practices must be carried out throughout the school year, not only in a quarter.

KEYWORDS: formation of readers; theatrical practices; literary readers. 


\section{INTRODUÇÃO}

Partindo do pressuposto de que o trabalho com práticas teatrais na escola colabora com o desenvolvimento cognitivo, afetivo e emocional dos participantes, promove a interação social, e, especialmente, contribui com a cooperação entre indivíduos, mostrando a importância do trabalho em equipe, pensamos em dar um passo a mais pensando na relação de tais práticas com a formação do leitor literário.

Como ponto de partida, realizamos uma pesquisa bibliográfica no banco de teses e dissertações da CAPES $^{3}$ com base em palavras-chave relacionadas ao tema como, por exemplo, formação de leitores; práticas teatrais; texto teatral; teatro e literatura, teatro e escola, entre outras. Não foram poucos os resumos que continham estas palavras; no entanto, raros foram os trabalhos que abordaram a contribuição das práticas teatrais para a formação de leitores literários na escola. A maioria dos trabalhos encontrados abordavam a importância do teatro para o desenvolvimento cognitivo e afetivo e para a interação social dos alunos. Encontramos também trabalhos que tematizavam a importância das práticas teatrais para o tratamento/recuperação de pessoas com doenças graves, como por exemplo, o câncer e a doença de Parkinson.

Além disso, apareceram diversas pesquisas sobre adaptações de obras literárias para os palcos, mas com outros objetivos, que não a formação de leitores literários. Sendo assim, justificamos a relevância da pesquisa, primeiramente, devido à pouca produção sobre a contribuição de práticas teatrais para formação de leitores literários; em segundo lugar, pela relevância do caráter pedagógico do teatro através dos tempos e pela pertinência de pensar a formação de leitores a partir de textos desafiadores do ponto de vista estético e formal como o texto teatral avaliando o efeito de práticas teatrais efetivadas na escola para esta formação.

A seguir, apresentaremos na segunda seção os pilares que deram sustentação teórica à pesquisa; na seção de número três, trazemos o aporte; a quarta seção apresenta a análise da prática efetuada por meio dos dados obtidos e, em seguida, fechamos com as considerações finais.

3 Coordenação de Aperfeiçoamento de Pessoal de Nível Superior (Capes) 


\section{PILARES TEÓRICOS}

Para a reflexão proposta é importante falar sobre leitura, formação do leitor literário e a relação desses eixos com as práticas teatrais. Além disso, teceremos algumas palavras sobre a teoria da adaptação.

\section{LEITURA, FORMAÇÃO DO LEITOR LITERÁRIO E PRÁTICAS TEATRAIS}

Para iniciarmos a reflexão teórica, escolhemos partir do questionamento sobre "o que é leitura?". Para respondermos a esta questão, apoiamo-nos em Silva (2009, p. 23) ao trazer pelo menos três tipos de leitura ou três atitudes do leitor durante o ato de ler: i) leitura mecânica, que consiste na habilidade de decifrar códigos e sinais; ii) a leitura de mundo, que consiste na habilidade de ler o mundo, marcada pela subjetividade de cada um, referenciada por Paulo Freire; e, iii) a leitura crítica, que une a leitura mecânica à de mundo, numa postura avaliativa, perspicaz, tentando descobrir intenções, comparando a leitura daquele momento com outras já feitas, questionando e tirando conclusões.

O terceiro tipo de leitura - a crítica - está num patamar que não se atinge de repente, pois exige um percurso por parte do leitor e é preciso que este tenha uma bagagem cultural que começa na infância e vai se ampliando ao longo dos anos. Segundo a autora, para fazer tal leitura é necessário estar com a mente alerta e ser capaz de relacionar, confrontar, chegar a sínteses e conclusões. Não é dom que define o leitor crítico e sim o aprendizado constante e principalmente a prática, ou seja, quanto mais o aluno lê mais ele se aproxima desse nível de letramento. Para tal, os professores e professoras devem atuar com um guia na escola direcionando seus alunos adiante nessa trajetória. E aí que a literatura entre em cena.

Sobre a literatura infantil e a formação de leitores, Zilberman (2003) apresenta alguns pontos que podem atrapalhar a compreensão da leitura de textos e a assimilação individual da realidade que, "sem ser compreendida na sua totalidade, ela não é autenticamente lida" (ZILBERMAN, 2003, p. 28). Tais pontos podem ser exemplificados pela redução do texto por parte do professor ao utilizar o livro em sala de aula 
com vistas a apontar aspectos certos ou errados; usar o texto literário como pretexto para ensinar gramática, ignorando as questões artísticas e subjetivas que uma obra literária carrega; quando pede-se preenchimento de fichas de leituras, o que implica respostas uniformizadas; e, também, quando as visões que cada criação literária desencadeia são simplificadas, deixando de lado as interpretações pessoais que decorrem "da compreensão que o leitor alcançou do objetivo artístico, em razão de sua percepção singular do universo representado" (ZILBERMAN, 2003, p. 28). Em relação ao papel do leitor e a formação de leitores, nas palavras da autora,

Não é atribuição do professor apenas ensinar a criança a ler corretamente; se está a seu alcance a concretização e expansão da alfabetização, isto é, o domínio de códigos que permitem a mecânica da leitura, é ainda tarefa sua o emergir do deciframento e compreensão do texto, pelo estímulo do deciframento e compreensão do texto, pelo estímulo da verbalização da leitura procedida, auxiliando o aluno na percepção dos temas e seres humanos que afloram em meio à trama ficcional (ZILBERMAN, 2003, p. 29).

Ou seja, cabe ao professor proporcionar mais do que a decodificação de códigos às crianças, pois independentemente da idade, estes leitores podem ser leitores críticos. Logo, o professor precisa promover atividades e construir com os alunos caminhos de leitura para uma melhor compreensão dos textos, sobretudo ensiná-los e ler nas entrelinhas, tendo em vista que as obras literárias apresentam recursos para que estes leitores se tornem críticos. Além disso, percebemos a função formadora da literatura infantil, que não pode ser confundida com missão pedagógica, a literatura acaba por dar conta "de uma tarefa que está voltada toda a cultura - a de conhecimento do mundo e do ser" (...) (ZILBERMAN, 2003, p. 29).

Ao falar sobre o estímulo à leitura, Colomer (2007) faz uma crítica ao modo como os livros são apresentados às crianças, pois antigamente "as crianças, das minorias ilustradas cresciam com os livros. Mães, perceptoras, famílias, visitas, o círculo social inteiro em que viviam, não se compreenderia sem referências aos livros" (COLOMER, 2007, p. 103). Estas crianças eram alfabetizadas na escola, aprendiam a decodificar os códigos, liam diversos livros e depois ouviam dos professores as expli- 
cações sobre o sentido dos textos. Quando começaram a se preocupar com as outras crianças, a ideia de que a escola já ensinava a ler cresceu, logo levavam livros até os leitores e isso era suficiente. Durante décadas esta ideia permaneceu, não se pensava em promover novos métodos para apresentar os livros às "novas” crianças.

Atualmente este problema persiste e, segundo Colomer (2007), está mais complexo, visto que, já não se limita às “novas crianças”. Devido a extensão da escolaridade, nos dias que correm, sabemos que se lê mais do que nunca, "mas o que se lê e para que se lê está longe de corresponder à literatura e a seus possíveis benefícios" (COLOMER, 2007, p. 104). Sobre os possíveis benefícios da literatura e da leitura literária D’Avila Et.All diz que,

A literatura é capaz de ampliar a capacidade de "lermos" o mundo, visto que ela é completa de conhecimentos sobre o homem e o que nos cerca. Além disso, a leitura literária auxilia na formação de sujeitos mais críticos e criativos, qualidades estas imprescindíveis no mundo moderno. (D'AVILA et. al., 2013, p. 157).

A autora deixa explícito que a literatura tem papel fundamental para a formação do leitor, pois o transforma, amplia seus horizontes, faz com que o leitor sinta emoções, além de contribuir para a nossa construção enquanto sujeitos da sociedade. Dentre os métodos que podem auxiliar a formação do leitor literário, Colomer (2007) destaca que as crianças - meninos e meninas - precisam de tempo para praticar a leitura individual em sala de aula; alguém que possa responder às curiosidades históricas destas crianças; que sejam dados aos meninos e meninas o significado das palavras sem que estes remetam-se à demora do dicionário; que sejam feitas apresentações sobre as obras que serão lidas com o intuito de despertar o interesse pela história contida nelas. Além disso, acreditamos que atividades em sala de aula, como rodas de conversa, debates sobre a temática dos textos, leituras dramáticas, também são capazes de desenvolver a formação desses leitores. No entanto, como este projeto tem foco nas práticas teatrais, veremos os possíveis efeitos destas práticas no próximo capítulo, em que apresentaremos teorias que justificam a importância do trabalho com práticas teatrais para a formação de leitores literários. 
Ainda sobre leitura, retomamos as teorias de Silva (2009) para compreendermos quais as etapas de leitura/tipos de leitor. Segundo a autora o percurso trilhado pelo leitor em seu processo de formação reflete sua crescente competência, esta pode ou não condizer com a série escolar em que o leitor se encontra e com a sua idade cronológica. Seis etapas são apresentadas por Silva (2009), sendo que as quatro primeiras devem ser completadas na primeira fase do Ensino Fundamental.

Pré-leitor (apenas ouve uma narrativa ser lida ou contada; ou lê uma narrativa guiado pela sequência de suas imagens, ou ainda, com a ajuda de um adulto); Leitor iniciante (lê sem ajuda textos breves e facilitados); Leitor em processo (lê textos de dificuldade média, seja em relação ao vocabulário, à construção da narrativa ou ao uso da linguagem); Leitor competente (lê textos mais complexos é capaz de reconhecer artifícios de construção, bem como estabelecer conexões entre diversas leituras) (SILVA, 2009, p. 25).

De acordo com a autora, quando o aluno ingressar no Ensino Médio deverá ter atingido o seguinte nível:

Leitor crítico (lê com total autonomia textos de qualquer extensão identificando alusões e subentendidos, assim como estabelecendo relações entre o texto lido e a realidade que conhece em suas vivências diárias de cidadão, sendo inclusive, capaz de emitir juízos críticos sobre o texto lido) (SILVA, 2009, p. 25).

Porém, a trajetória de leitura nem sempre acompanha o desenvolvimento físico ou a progressão escolar do leitor. Sendo assim ressaltamos a importância do professor, como mencionamos anteriormente, em promover atividades que contribuam para a formação desses leitores, especialmente ao explorar a leitura literária, uma vez que é por meio dela que se desperta a imaginação, permite que entremos na pele dos personagens e que sintamos suas emoções, nos transformando e ampliando nossas visões de mundo. Diante do exposto, podemos aproximar os benefícios da leitura literária às práticas teatrais, pois ao realizarmos, por exemplo, uma leitura dramatizada, precisaremos imaginar um cenário, criar um perfil para o personagem a fim de fazer uso de suas emoções. 
Para Silva (2009, p. 132), “os jogos dramáticos de várias modalidades podem ser grandes aliados do professor na formação intelectual, social e humana de seus alunos". Atividades teatrais proporcionam prazer, diversão, desenvolvem aspectos cognitivos, afetivos e sociais. Além disso, conforme o autor, um dos frutos destas atividades é a desinibição da fala e desta decorre também a desinibição do uso do corpo. Em suas palavras, os jogos dramáticos propiciam o rompimento do imobilismo que paralisa a expressão da voz e do corpo dos mais tímidos contribuindo para seu processo de autoafirmação.

As sucessivas leituras que se fazem antes de encenar uma peça, buscando entender suas intenções e transformá-las no tom de voz (leitura expressiva) e na expressão corporal apropriada beneficiam indiretamente a leitura de outros textos literários, pois desperta no aluno um olhar perspicaz, crítico. Constituem, então, mais do que uma simples atividade divertida, um aprendizado de vida (SILVA, 2009, p. 134).

Ao realizar as leituras pré-espetáculo, entramos em contato com outras leituras como, por exemplo, ao pesquisar a história de um determinado personagem com o intuito de conhecê-lo melhor e representá-lo de forma fiel, ou quando desconhecemos uma palavra e buscamos seus significados, uma leitura leva a outra, e deste modo enriquecemos nosso aprendizado. Ao buscar pela história de um personagem, ou sobre algum fato histórico, estamos ampliando nosso conhecimento, aumentando nossa bagagem cultural e evoluindo enquanto leitores. Conforme Reverbel (1978):

Um recurso de formação de leitores que pode motivar, contagiar o aluno para o hábito de ler, em todos os graus de ensino, é o teatro. $\mathrm{O}$ teatro auxilia o estudante no aprendizado de um determinado conteúdo ao mesmo tempo em que oferece possibilidades de diverti-lo (REVERBEL, 1978, p. ?).

Como citamos acima, e relacionando com o excerto de Reverbel (1978), as práticas teatrais além de divertir, de proporcionar prazer, de desenvolver aspectos cognitivos, afetivos e sociais, são recursos que contribuem para a formação de leitores literários na escola. Em face à escassez de trabalhos que apontem os benefícios destas práticas, motivo pelo qual justificamos os estudos deste projeto, traremos a seguir o 
percurso metodológico compreendendo à atividade feita in loco em uma escola do interior do Rio Grande do Sul, com uma turma de terceiro ano e, posteriormente, analisaremos esta atividade, buscando ampliar o conhecimento acerca das questões envolvendo a temática da formação do leitor literário por meio das práticas teatrais.

\section{A IMPORTÂNCIA DA TEORIA DA ADAPTAÇÃO}

Para falarmos acerca do processo da escrita dos esquetes por parte dos alunos, precisamos pensar na teoria da adaptação. Toda vez que falamos em adaptação temos a tendência em pensar em clássicos e suas adaptações para o cinema, como por exemplo, Harry Potter e Jogos Vorazes. No entanto, pensar somente neste tipo de adaptação seria reduzir o imenso universo da adaptação. Conforme Hutcheon,

Os vitorianos tinham o hábito de adaptar quase tudo - e para quase todas as direções possíveis; as histórias de poemas, romances, peças de teatros, óperas, quadros, músicas, danças (...) eram constantemente adaptados de uma mídia para outra, depois readaptados novamente (HUTCHEON, 2013, p. 11).

Apesar de contarem com poucos materiais, os vitorianos adaptavam e readaptavam com frequência. Atualmente, com muito mais recursos a adaptação está fora de controle, se levarmos em consideração apenas filmes e romances seremos incapazes de entender o apelo e a natureza da adaptação. Hutcheon (2013) busca pensar na adaptação e suas várias encarnações midiáticas. No entanto, nos deteremos a abordar os aspectos da adaptação que tratam de textos narrativos adaptados para o teatro.

A autora explica que qualquer texto adaptado tem a tendência de ser considerado inferior ao texto que lhe deu origem, no entanto, é importante pensar que "a arte deriva da arte, as histórias nascem de outras histórias" (HUTCHEON, 2013, p. 22). A adaptação pode se dar tanto entre gêneros e mídias diferentes, como dentro de um único gênero e uma única mídia.

O produto e o processo de adaptação não existem num vácuo, ou seja, é necessário um contexto para que a adaptação ocorra. São diversos os motivos que le- 
vam uma pessoa a adaptar, por exemplo, ao adaptar um texto narrativo para o teatro o autor pode estar querendo prestar uma homenagem ao autor da obra. Mas afinal o que é adaptar? Nas palavras da autora:

(...) a adaptação é uma transposição anunciada e extensiva de uma ou mais obras em particular. Essa "transcodificação" pode envolver uma mudança de mídia (de um poema para um filme) ou gênero (de um épico para o romance), ou uma mudança de foco e, portanto, de contextos: recontar a mesma história de um ponto de vista diferente, por exemplo, pode criar uma interpretação visivelmente distinta (HUTCHEON, 2013, p. 29).

Portanto, independente dos motivos que levam uma pessoa a adaptar ou por mais que o texto adaptado seja fiel ao texto "fonte", ainda assim será considerada uma adaptação. Logo, a partir do momento em que solicitamos que os alunos "transformassem" um texto narrativo, neste caso um conto, em um texto teatral, já estávamos nos apropriando da teoria da adaptação. No subitem "da observação das adaptações” dentro do item análise de dados, buscamos compreender como se deu o processo de adaptação e quais os motivos que os levaram a adaptar.

\section{APORTE METODOLÓGICO}

A pesquisa em questão trata-se de um estudo qualitativo, uma vez que foi elaborado sem a pretensão de analisar índices e níveis, prezando sempre pelo acompanhamento do processo pessoal de cada aluno e a forma como correspondiam às atividades propostas em sala de aula. Inicialmente, a análise da evolução e construção dos resultados dessas práticas, dariam-se somente pelos questionários, nos quais os alunos poderiam discorrer livremente acerca das aulas e, para facilitar a honestidade dos relatos - fator imprescindível para a conclusão desse projeto - optamos pelo anonimato de cada estudante. Entretanto, com o decorrer das aulas, pôde-se facilmente observar resultados positivos, pois alguns alunos começaram a pedir livros emprestados à pesquisadora e à biblioteca, representando a eficiência da utilização das práticas teatrais. 
O projeto de ensino intitulado "Práticas teatrais nas aulas de literatura: caminhos possíveis para a formação de leitores" foi aplicado em uma turma de $3^{\circ}$ (terceiro) ano do Ensino Médio de uma escola pública de uma cidade do interior do Rio Grande do Sul. O projeto de ensino planejado e aplicado foi de 11 (onze) horas aula (h/a) e foi supervisionado pela professora regente da turma. Apresentou uma proposta de atividades baseada em práticas teatrais em busca de caminhos possíveis para a formação de leitores literários na escola. A proposta foi pensada para o ensino de Literatura, sendo assim, justifica-se esta prática pela necessidade de aproximar os alunos da leitura de obras canônicas, por meio de práticas teatrais.

O conto escolhido para ser trabalhado com a turma foi o conto Negrinha, de Monteiro Lobato. A escolha deste conto deu-se através da leitura do plano da disciplina da professora regente da turma e levou-se em consideração que, no momento em que o projeto foi aplicado, a Escola Literária em estudo era o Modernismo.

Durante a execução do projeto foram desenvolvidas práticas teatrais com o intuito de aproximar os alunos leitores do texto, visando a criação e apresentação de um esquete ${ }^{4}$ baseado no conto Negrinha. Além disso, foram desenvolvidas atividades de leitura e interpretação de texto, foram aplicadas práticas teatrais com diferentes objetivos, por exemplo, desinibição e atividades de expressão corporal.

Para que os alunos pudessem produzir o esquete, durante as aulas, abordamos questões sobre a história do teatro, apresentamos vídeos de esquetes para que os alunos que, até o momento, não tinham ido ao teatro, tivessem a oportunidade de compreender minimamente o que era uma peça teatral. Além disso, levamos para as aulas livros teóricos sobre o teatro e de peças teatrais, sendo que alguns livros eram da própria biblioteca da escola. Disponibilizamos livros que continham termos técnicos específicos de teatro e propusemos o levantamento das obras dramáticas disponíveis na biblioteca com o objetivo de aproximar os alunos de tais escritos para que estes pudessem entender a estrutura do texto teatral, incentivando-os a conhecerem o acervo consideravelmente vasto da biblioteca de sua escola.

4 Peça teatral de curta duração. 
Além da aplicação do projeto de ensino, contamos com três instrumentos de pesquisa, sendo: o questionário, as observações das aulas registradas em diário de campo e questões sobre adaptações de acordo com o exposto teórico sobre.

O questionário foi pensado com o intuito de compreendermos se as práticas aplicadas durante as aulas mudariam a relação dos alunos com a leitura e compreensão do texto literário. Os questionamentos "O que motiva você a ler? (O que faz você ir atrás de um texto para ler?)” e “Qual sua relação com a leitura?”, foram feitos no primeiro dia de aula e tinham, por objetivo, compreender a relação dos alunos com a leitura. A fim de conseguirmos compreender o que mudou após a aplicação do projeto de ensino, na última aula do projeto de ensino, foram realizadas as seguintes perguntas: "As práticas desenvolvidas ao longo deste trimestre motivaram você a ler? Sua relação com a leitura mudou? Justifique."

A análise apresentada a seguir retrata o diálogo com os dados obtidos por meio dos instrumentos apresentados.

\section{ANÁLISE DOS DADOS}

\section{DAS OBSERVAÇÕES SOBRE A PRÁTICA}

Para melhor andamento do projeto, cada aula foi pensada e planejada individualmente. Após cada aula, fazíamos anotações sobre o andamento das aulas e sobre aspectos que considerávamos relevantes em relação aos alunos. Estas anotações serviram como instrumento para compreender os efeitos do trabalho com práticas teatrais em sala de aula.

Na primeira etapa, foi aplicada uma dinâmica de interação. No entanto menos da metade da turma quis participar, pois estavam tímidos. Pudemos perceber como as práticas ajudaram no quesito timidez, sendo que no dia da apresentação dos esquetes, apenas dois alunos não quiseram apresentar seus trabalhos. Estes alunos 
optaram por adaptar o conto Negrinha, individualmente, pois conforme justificaram, não gostavam de trabalhos em grupo.

Na etapa 3, da aplicação do projeto de ensino, foi realizada uma roda de leitura, em que cada aluno leria um trecho do conto. Após a leitura foi realizada uma discussão acerca das temáticas presentes no texto, durante esta conversa os alunos destacaram a violência contra as crianças, o preconceito, a violência contra a mulher, além de demonstrarem certo desconforto com a ironia usada por Monteiro Lobato ao falar da personagem Dona Inácia. Esta etapa foi de extrema importância para a escolha da adaptação dos alunos, como pode ser vista com mais detalhes no item seguinte.

Na etapa quatro, levamos livros para sala de aula. Além de textos teóricos sobre o teatro, foram levados textos adaptados para o gênero dramático. Neste momento, os alunos solicitaram o empréstimo de livros e mostraram-se surpresos ao saber que haviam tantas obras com a temática teatro na biblioteca da escola. Esta etapa foi de extrema importância, pois despertou a curiosidade dos alunos em conhecer melhor a biblioteca da escola, além do fato de alguns alunos terem feito empréstimos de livros.

A seguir veremos a importância do processo de adaptação.

\section{DAS OBSERVAÇÕES SOBRE AS ADAPTAÇÕES}

É importante analisar, mesmo que brevemente, como se deu o processo de adaptação por parte dos alunos, tendo em vista, a importância da escolha dos alunos, o que reflete suas vivências e visões de mundo.

A turma foi dividida em quatro grupos. Antes de solicitarmos aos alunos a adaptação do conto Negrinha, de Monteiro Lobato, foi construído com os alunos a compreensão sobre adaptação. Foram mostrados exemplos de adaptações e, além disso, os alunos tiveram contato com textos teatrais para que pudessem entender sua estrutura.

O Grupo 01 escolheu a parte do conto para adaptar em que trazia a descrição da personagem Dona Inácia e a explicação do narrador sobre as visitas que suas amigas e o vigário faziam a ela. Os alunos, com base no trecho escolhido, criaram diálogos 
e o assunto que permeava esta conversa era a bondade de Dona Inácia ao adotar a personagem Negrinha. Houve certa preocupação por parte dos alunos, pois o grupo era composto somente por meninos. Foi explicado a eles que podiam ficar à vontade em encenar uma personagem feminina ou adaptarem e transformarem em um personagem masculino. No entanto, como nenhum aluno quis representar Dona Inácia, este grupo adaptou e então tivemos o personagem Inácio, seus amigos e o padre. Ao perguntarmos o porquê deste trecho, os alunos responderam que além de facilitar a transformação para personagens masculinos, este trecho chamava a atenção pelo fato da personagem Inácia ter "camarote de luxo reservado no céu" e por uma senhora branca ter adotado uma criança negra filha de negros escravizados.

O Grupo 02 fez uma adaptação mais fiel à história e foi o primeiro a apresentar listagem de personagens no início do texto e rubricas ao longo do mesmo. $\mathrm{O}$ trecho escolhido por este grupo de alunos foi a parte em que as sobrinhas de Dona Inácia foram passar as férias com ela. A personagem Negrinha teve a oportunidade de finalmente brincar, vivenciando pela primeira vez momentos de criança, no qual descobriu o sentido da palavra felicidade. Porém, após as sobrinhas irem embora, Negrinha vê-se obrigada a retomar sua triste realidade e acaba morrendo de tristeza. Os alunos deste grupo relataram sua escolha por terem se impressionado com o fato de Negrinha nunca ter brincando e também pelo fato de a personagem sendo menina e criança, não sabia o que era uma boneca.

O Grupo 03, também foi fiel à história. O grupo optou pela parte da história em que Negrinha foi castigada por Dona Inácia, após chamar a criada de "peste". Ela faz Negrinha comer à força um ovo quente, com casca e tudo, para que ela nunca mais falasse nomes feios aos mais velhos. Neste caso, os alunos justificaram sua escolha devido à violência com a qual Negrinha, uma criança, foi castigada.

Por fim, o Grupo 04, utilizou-se de alguns trechos do texto para a sua adaptação, dando um novo olhar para a história. Este grupo composto de cinco meninas e um menino tinha um diferencial, já que o menino (vamos chamá-lo de Aluno A) tinha 17 anos na época em que o projeto fora aplicado. O Aluno A era participante de atividades teatrais desde os oito anos de idade, principalmente como ator, mas também já havia escrito e dirigido uma peça. Abrimos este parênteses para compreendermos 
o porquê o esquete do grupo foi tão diferente dos demais. O aluno A representou o personagem Inácio e as demais integrantes do grupo representaram personagens femininos. A adaptação deste grupo recebeu o título: "O sangue é da mesma cor" e conta a história de Negrinha, uma menina negra de sete anos, órfã, que é castigada com frequência. Na texto elaborado por eles, além da temática do conto, entrou em cena a temática da aplicação de nosso projeto de ensino:

(...)Acredita que ouvi boatos que uma professora de uma outra escola estava incentivando os alunos a lerem histórias com o uso de teatro?

Veja lá se isso é importante. Achas que quero que meus criados saibam ler? Que eles pensem por si próprios?

Questionados sobre o motivo de falarem acerca do teatro e a formação de leitores, os alunos ressaltaram que o teatro é uma das formas de incentivo à leitura, falaram também, sobre a importância de aulas mais dinâmicas que utilizam recursos como, por exemplo, a música, o teatro e até mesmo desenhos para aproximar os alunos dos conteúdos do currículo.

O Grupo 04 ao final da sua história abordou uma situação delicada no nosso país: a violência. Contra mulheres e contra os negros:

\section{Madre/Sobrinha 2}

A cada 23 minutos, um jovem negro é assassinado no Brasil, pelo simples fato de ser negro.

\section{Mãe/sobrinha 1}

A cada hora, 500 mulheres são agredidas no Brasil

\section{Todos}

Agora imagina, negra e mulher?

\section{Inácio}

A nossa Negrinha era branca porque, infelizmente, como reflexo da escravidão e fruto do racismo, somente agora está aumentando o número de negros em sala de aula.

\section{Todos}

O sangue é da mesma cor. 
Percebemos que este grupo buscou contar a trajetória da protagonista Negrinha tal qual o conto, mas incluiu a importância do teatro como incentivo à leitura, valorizando a importância da leitura na vida das pessoas e o papel social e pedagógico que uma encenação pode ter. E por fim, mas não menos importante, pesquisou dados atuais sobre a violência contra os negros no Brasil, deixando claro que o aspecto que mais chamou a atenção deles no conto de Monteiro Lobato foi a violência contra Negrinha.

Podemos observar que os três primeiros grupos optaram por serem mais fiéis ao texto lido como fonte em suas adaptações, enquanto o grupo 04 acrescentou informações e deu um novo olhar, ou seja, fizeram uma releitura do conto. Num primeiro momento pode parecer que apenas o último grupo fez, de fato, uma adaptação, no entanto, segundo Hutcheon (2013):

A adaptação é repetição, porém, repetição sem replicação. E há claramente várias intenções possíveis por trás do ato de adaptar: o desejo de consumir e apagar a lembrança do texto adaptado, ou de questioná-lo, é um motivo tão comum quanto a vontade de prestar uma homenagem, copiando-o (HUTCHEON, 2013, p.28).

Ou seja, todos os grupos realizaram uma adaptação sendo que a diferença dessas adaptações são visíveis quando olhamos para os motivos que basearam a escolha dos grupos por este ou aquele trecho. Além disso, houve a adaptação de gênero narrativo para o gênero dramático (HUTCHEON, 2013, p. 29).

\section{DAS OBSERVAÇÕES DAS ENTREVISTAS}

Um primeiro ponto a ser destacado é a maneira como os próprios alunos se enxergam, pois esses jovens não se reconhecem como leitores. O currículo engessado é uma das hipóteses que criam o imaginário de que um leitor é apenas aquele que lê livros literários. A maioria dos alunos que respondeu aos questionários não se consideram leitores e dizem ter uma relação de ruim a mediana com a leitura pelo fato de não terem o costume de lerem livros literários. Como exemplo, o aluno chamado aqui de Aluno 21 apresenta a seguinte fala: 
Na verdade, não tenho tanta relação com a leitura porque eu não sou aquela pessoa que mergulha nos livros, porém estou sempre me informando, acho a leitura essencial para todos (Aluno 21).

O aluno sugere que faz outras leituras, além de considerar que ler é de suma importância para adquirir conhecimento. Esse leitor, para se tornar um leitor literário, um leitor que não só decodifica os códigos linguísticos, precisa primeiramente se ver como um leitor.

Em seguida precisamos destacar o que motiva o aluno a ler. Ao perguntarmos sobre, a maioria das respostas dos estudantes são "assunto", ou seja, eles escolhem suas leituras de acordo com seus interesses e com a capa do livro. Sobre o segundo item vemos um forte apelo pelo visual, aqueles livros antigos com uma capa sem graça e escura aparentemente não chama atenção dos jovens, talvez por isso haja uma movimentação tão forte das editoras em atualizar as capas de livros antigos dos grandes clássicos. Embora essa problemática seja pertinente, podemos encarar isso como um incentivo à leitura literária, digamos que uma porta de entrada. À medida que o sujeito vai se familiarizando com os textos, ele vai entendendo que a beleza de um livro literário vai além de uma capa bonita.

Outro fator que apareceu como incentivador da leitura foi a indicação de outras pessoas, sejam elas amigos ou colegas. O gosto pela leitura pode ser contagiante, e partindo do princípio de que os alunos se interessam pela leitura por causa do assunto, quanto mais pessoas falando sobre suas leituras, o interesse pode atingir um número cada vez maior de pessoas. Fato curioso é que um aluno apenas citou obrigatoriedade como algo que o faz ler:

(...)Não tenho boa relação com a leitura, pois só leio quando me chama muito atenção ou quando sou obrigada a ler alguma coisa (Aluno 25).

Isso nos faz pensar que nem como fator obrigatório a literatura está aparecendo nas escolas ${ }^{5}$. As leituras ditas obrigatórias estão desaparecendo das aulas de literatura. Como incentivar um aluno a ler se nem nas aulas os livros aparecem?

5 Não queremos com isso generalizar uma situação. Apresentamos hipóteses advindas de nossa experiência em sala de aula. 
O Aluno 22 diz que: "Agora não tenho tanta relação com os livros, não leio direto como antigamente, leio mais textos que vejo nas redes sociais diariamente." Onde está a escola que não incentiva e media esse contato? Quais motivos levam a escola a renegar esse novo e vasto tipo de leitura? São questionamentos que precisam de respostas.

Sobre o questionamento se as práticas motivaram os alunos a ler, positivamente a grande maioria respondeu que sim, mas temos que observar que quase todos os alunos que responderam já possuíam contato com a leitura, seja literária ou não. Um aluno apenas afirmou não ter contato e que o projeto despertou o seu interesse por meio das atividades propostas. Também tivemos um aluno que havia perdido o hábito e o prazer de ler e com as aulas indica que voltou a ter interesse.

O Aluno 9 diz "[... com as práticas teatrais tive mais interesse em ler, principalmente livros, que não gostava de ler". Tal aluno já era leitor de receitas, jornais, mas a prática teatral despertou nele o interesse pela leitura literária especificamente. Já o Aluno 6 demonstra outra possibilidade que o teatro pode despertar nos alunos: a desinibição, uma vez que "não me motivaram a ler (as práticas), apenas me motivou a me expor mais, me soltar mais". Ao observarmos a resposta do Aluno 11, percebemos que o incentivo para ler vem de outro colega que já faz parte de um grupo de teatro:

(...) Sim, nesse trimestre li meu primeiro livro incentivado por uma colega que já fez teatro e estava bem interessada depois de me apresentar com minhas colegas (Aluno 11).

Ao conhecer algumas respostas dos alunos ao questionário, podemos concluir que sim, experiências com práticas teatrais é capaz de incentivar a leitura, formar leitores críticos e também cidadãos capazes, engajados e atuantes em questões sociais e humanas. Se o aluno não tem contato com livros nem com literatura nas aulas, é possível propor uma prática eficaz? Se sim, será que as práticas que estão sendo aplicadas nas escolas são ideais? 


\section{CONSIDERAÇÕES FINAIS}

Apesar de o tempo de aplicação do projeto de ensino tenha sido curto, nos mostrou que a prática teatral é uma ideia que, se trabalhada de forma planejada, fundamentada teoricamente, divertida, atrativa e dinâmica tem muita potência para promover uma grande virada na forma de aprender literatura e resgate de toda uma geração de leitores literários. No papel de formadores e pesquisadores, afirmamos que o trabalho nos proporcionou refletir também sobre o processo de adaptação e suas implicações.

Acreditamos que um trabalho como o por nós desenvolvido traria resultados ainda melhores se fosse aplicado ao longo do ano letivo e no decorrer dos anos não só do ensino médio, mas de toda a educação básica. Assim, talvez, pudéssemos ampliar a visão dos alunos sobre o que é ser leitor, especialmente, leitor literário.

A problemática acerca desse assunto é muito complexa e as aulas de língua portuguesa e literatura, por exemplo, deveriam ser espaços para oferecer aos alunos subsídios mínimos para ler um texto dramático e até mesmo prepará-los para encená-lo. O ensino de literatura no ensino médio ainda se baseia na leitura de trechos e curiosidades sobre a vida dos autores, sendo que uma minoria de professores que tentam trabalhar com o teatro em sala de aula cai na armadilha de focar apenas nos jogos teatrais, deixando de lado o aprofundamento no texto literário em si.

A experiência, enfim, nos mostra que trabalhar com práticas teatrais não é uma tarefa fácil; precisa haver uma mudança de postura principalmente no sistema educacional. Os alunos precisam ter contato desde cedo com os livros e seus textos integrais. Eles precisam se apropriar da literatura e isso só é possível lendo muito e por meio de incentivo que deve vir do espaço escolar. 


\section{REFERÊNCIAS}

Abril. Teatro Vivo: introdução e história. São Paulo: Abril Cultural, 1976.

COLOMER, Teresa. Andar entre livros: a leitura literária na escola. Tradução de Laura Sandroni. São Paulo: Global, 2007.

D’Avila Et. All. Do mundo da teoria para os efeitos da teoria no mundo: diálogos entre forma(n)dos em perspectiva. In: ALVAREZ, I. M. J. GIOVANI. F. (Orgs.) Embates dialógicos nas formações inicial e continuada: significando práticas e constituindo olhares. São Paulo: Pedro e João Editores, 2013.

DÓRIA, Lílian Maria Fleury Teixeira. Linguagem do teatro brasileiro. Curitiba: InterSaberes, 2012.

HUTCHEON, Linda. Uma teoria da adaptação. Tradução de André Cechinel. 2.ed. Florianópolis: Ed. Da UFSC, 2013.

KOUDELA, Ingrid. Jogos teatrais. São Paulo: Perspectiva, 2006.

MAGALDI, Sábato. Panorama do teatro brasileiro. 6. ed. São Paulo: Global, 2004.

MARLI ANDRÉ. Pesquisa em educação: buscando rigor e qualidade. In: Cadernos de pesquisa, n. 113, p. 51 - 64. Julho, 2001. Disponível em: <http://nead.uesc. br/arquivos/Biologia/modulo_7_bloco_1/tcc/texto_2_pesquisa_em_educacao_buscando_rigor_e_qualidade.pdf>. Acesso em: julho de 2018.

PAVIS, Patrice. Dicionário de teatro. São Paulo: Editora Perspectiva, 2008.

PEIXOTO, Fernando. O que é teatro? (Coleção Primeiros Passos). São Paulo: Brasiliense, 2006.

REVERBEL, Olga. Jogos teatrais na escola: atividades globais de expressão. São Paulo: Scipione, 2002.

REVERBEL, Olga. Teatro na sala de aula. Rio de Janeiro: José Olympio, 1978.

SILVA, Vera Maria. Leitura literária \& outras leituras: impasses e alternativas no trabalho do professor. Belo Horizonte: RHJ, 2009.

SPOLIN, Viola. Jogos teatrais na sala de aula: um manual para o professor. Tradução de Ingrid Koudela. 3. ed. São Paulo: Perspectiva, 2015.

ZILBERMAN, Regina. A literatura infantil na escola. 11. ed. São Paulo: Global, 2003. 